\title{
Uso de métodos complementares na inspeção post mortem de carcaças com suspeita de tuberculose bovina ${ }^{1}$
}

\author{
Leone V. Furlanetto ${ }^{2}$, Eduardo E.S. Figueiredo ${ }^{3 *}$, Carlos A. Conte Júnior ${ }^{2}$, Ricardo C.T. \\ Carvalho $^{3}$, Flavia G.S. Silva ${ }^{4}$, Joab T. Silva ${ }^{2}$, Walter Lilenbaum ${ }^{5}$ e Vania M.F. Paschoalin ${ }^{2}$
}

\begin{abstract}
Furlanetto L.V., Figueiredo E.E.S., Conte Júnior C.A., Carvalho R.C.T., Silva F.G.S., Silva J.T., Lilenbaum W. \& Paschoalin V.M.F. 2012. [Use of complementary methods in post mortem inspection of carcasses with suspected bovine tuberculosis.] Uso de métodos complementares na inspeção post mortem de carcaças com suspeita de tuberculose bovina. Pesquisa Veterinária Brasileira 32(11):1138-1144. Laboratório Microbiologia Molecular de Alimentos, Departamento de Alimentos e Nutrição, Universidade Federal de Mato Grosso, Cuiabá, MT, Brazil. Email: figueiredoeduardo@ufmt.br

The aim of this study was used diagnostic methods (histopathological, bacteriological and molecular) in the trial of suspected tuberculosis lesions observed during routine post mortem inspection in abattoirs. A total of of 41,193 cattle, which appeared healthy in ante mortem examination, slaughtered in seven abattoirs in the state of Mato Grosso, Brazil were examined. The carcasses of $198(0.48 \%)$ animals showed lesions, of which $182(91.9 \%)$ were classified as granulomatous or pyogranulomatous by histopathological analysis. However, at bacilloscopy, the presence of acid-fast bacilli (AFB) was not detected. Mycobacterium bovis was recovered from $3(1.5 \%)$ samples, all from retropharyngeal lymph nodes in cattle up to three years old. When multiplex PCR (m-PCR) was performed directly on fragments of injured tissue, M. bovis DNA was detected in 14 (7.0\%) samples including the same 3 bacteriologically positive samples. Evaluation of lesions by macroscopic analysis agreed 93\% (184/198) with bacteriological culturing and the molecular test. To avoid misinterpretation during the examination, mainly of paucibacillary lesions such as those found in the samples analyzed, the use of rapid and unequivocal complementary tests such as MPCR is recommended. Molecular diagnosis, combined with routine post mortem inspection, proved to be a promising technique to improve the surveillance of TB in abattoirs, contributing to the success of the bovine tuberculosis eradication program.
\end{abstract}

INDEX TERMS: Mycobacterium bovis, tuberculosis, macroscopic analysis, bacteriology, histopathology, multiplex PCR.

\footnotetext{
${ }^{1}$ Recebido em 9 de março de 2012.

Aceito para publicação em 13 de agosto de 2012

${ }^{2}$ Laboratório de Bioquímica e Biologia Molecular, Instituto de Química, Universidade Federal do Rio de Janeiro (UFRJ), Bloco A, Sala 545, Cidade Universitária, Rio de Janeiro- RJ 21941-909, Brasil.

${ }^{3}$ Laboratório de Microbiologia Molecular de Alimentos, Departamento de Alimentos e Nutrição, Universidade Federal de Mato Grosso (UFMT), Av. Fernando Correia da Costa s/n, Cidade Universitária, Boa Esperança, Cuiabá, MT 78060-900, Brasil. *Autor para correspondência: figueiredoeduardo@ufmt.br

${ }^{4}$ Unidade de Genética e Biologia Molecular, Hospital Geral Universitário, Universidade de Cuiabá, Rua 13 Junho, Centro, Cuiabá, MT 78025-000.

${ }^{5}$ Laboratório de Bacteriologia Veterinária, Instituto Biomédico, Universidade Federal Fluminense (UFF), Rua Hernani Melo 101, Sala 309, Niterói, RJ 24210-130, Brasil.
}

RESUMO.- 0 objetivo foi utilizar métodos complementares de diagnóstico (histopatológicos, bacteriológicos e moleculares), no julgamento de lesões suspeitas de tuberculose observadas durante a inspeção post mortem de rotina em abatedouros. Foi acompanhado o abate e a inspeção de 41.193 bovinos, sadios ao exame ante mortem, em sete abatedouros no estado de Mato Grosso. Carcaças de 198 $(0,48 \%)$ animais apresentaram lesões, sendo 182 (92,0\%) classificadas como granulomatosas ou piogranulomatosas na avaliação histopatológica. Entretanto, na baciloscopia, não foi evidenciada a presença de bacilo álcool-ácido resistente (BAAR). Mycobacterium bovis foi isolado em três $(1,5 \%)$ lesões, provenientes de linfonodos retrofaringeanos de bovinos com até três anos de idade. Quando usado 
a PCR múltipla (m-PCR) diretamente nos fragmentos de tecido, detectou-se a presença de DNA de $M$. bovis em 14 $(7,0 \%)$ lesões, incluindo as três amostras identificadas na análise bacteriológica. 0 julgamento das lesões pelo exame macroscópico concordou em 93,0\% (184/198) com os resultados obtidos por meio da PCR. A fim de evitar equívocos durante a avaliação, principalmente das lesões paucibacilares, como as encontradas neste estudo, recomenda-se a utilização de testes complementares rápidos e confirmatórios. A m-PCR, associada à inspeção post mortem de rotina, demonstrou ser uma técnica promissora para a vigilância da tuberculose bovina em abatedouros, contribuindo para o sucesso do programa de erradicação da tuberculose bovina.

TERMOS DE INDEXACAO: Mycobacterium bovis, tuberculose, histopatologia, bacteriologia, multiplex PCR.

\section{INTRODUCÃO}

A tuberculose bovina (TB) é uma zoonose de evolução crônica e efeito debilitante, causada por Mycobacterium bovis, cujo hospedeiro primário é o bovino. Entretanto, diversas espécies de mamíferos, incluindo o homem, também são susceptíveis á infecção por este micro-organismo. Esta doença é caracterizada pela formação de lesão do tipo granulomatosa, de aspecto nodular, denominada de "tubérculo" (Abrahão 1999).

Corner e colaboradores, em 1990, observaram que 70 a $76 \%$ das lesões causadas por TB, encontradas durante a inspeção post mortem de bovinos em abatedouros, ocorreram nos linfonodos da cabeça ou da cavidade torácica. Dentre as carcaças com tais lesões, até 74\% delas apresentaram uma única lesão, evidenciando assim, a importância da inspeção dos linfonodos para o diagnóstico desta doença. Porém, o diagnóstico post mortem anatomopatológico ou exame macroscópico, apresenta considerável dificuldade, uma vez que muitos processos inflamatórios granulomatosos possuem características morfológicas semelhantes às descritas para aquelas advindas da tuberculose (Reis et al. 1995).

Entre os métodos de diagnóstico que poderiam complementar a inspeção post mortem estão os testes histopatológicos, com coloração dos tecidos por hematoxilina-eosina (HE); a baciloscopia, com coloração por Ziehl-Neelsen (ZN); a cultura bacteriológica; e também testes moleculares baseados nas reações em cadeia da polimerase (PCR).

Os métodos histológicos empregados para o diagnóstico de tuberculose são rápidos e baratos, contudo, apresentam baixa especificidade e sensibilidade. 0 diagnóstico definitivo de tuberculose depende do isolamento e identificação do agente etiológico. No entanto, esta metodologia apresenta aspectos restritivos para uso em larga escala, pois requer uma grande quantidade de bacilos viáveis, 0 que não é frequente em infecções recentes; requer também o uso de métodos drásticos de descontaminação, podendo comprometer a eficácia do cultivo; e o crescimento fastidioso do agente (Corner 1994, Zanini et al. 2001).

Uma alternativa que permite a identificação rápida de micobactérias, encontradas em amostras clínicas ou em colônias isoladas, são os ensaios de PCR. Diversos estudos vêm demonstrando a possibilidade do uso desta técnica para a detecção de $M$. bovis em fragmentos de lesões sugestivas de tuberculose, permitindo assim, um aumento de sensibilidade, especificidade e diminuição no tempo de diagnóstico da infecção (Liebana et al. 1995, Wards et al. 1995, Zanini et al. 2001, Meickle et al. 2007, Cardoso et al. 2009).

Rotineiramente, a avaliação macroscópica durante a inspeção post mortem de TB em abatedouros é a única medida empregada para o diagnóstico da enfermidade, o que pode incorrer em erros na sua detecção, que por sua vez, podem resultar em prejuízos econômicos e sanitários, comprometendo o sucesso do programa de vigilância da tuberculose bovina. Este estudo teve por objetivo utilizar métodos complementares de diagnóstico (histopatológicos, bacteriológicos e moleculares) no julgamento de lesões suspeitas de tuberculose observadas durante a inspeção post mortem de rotina em abatedouros.

\section{MATERIAL E MÉTODOS}

Entre maio a outubro de 2009, foi acompanhado o abate e exame post mortem de 41.193 bovinos abatidos em sete abatedouros detentores de serviço de inspeção federal (SIF), localizados em seis municípios do estado de Mato Grosso, com efetivo de rebanho (Instituto Brasileiro de Geografia e Estatística 2007). Durante este período, os julgamentos atribuídos pelo SIF à tuberculose e às linfadenites localizadas nas regiões da cabeça, cavidade torácica ou cervical da carcaça (lesões suspeitas de TB, quanto a sua localização) foram registrados e fragmentos coletados dessas lesões.

As lesões foram avaliadas macroscopicamente conforme as normas oficiais do exame post mortem feita pelo SIF (Brasil 1952), fotografadas; divididas em amostras; e enviadas, devidamente acondicionadas, para a realização de exames histopatológicos e bacteriológicos, isto é, fixadas em formol tamponado a $10 \%$ ou mantidas congeladas a $-20^{\circ} \mathrm{C}$, respectivamente. Para as carcaças que apresentaram mais de uma lesão foi feito um agregado das mesmas, originando sempre uma amostra por animal.

Informações zootécnicas e dados relacionados à origem e condição sanitária dos animais, como: se participavam ou não do Programa Nacional de Controle e Erradicação da Brucelose e Tuberculose Animal (PNCEBT) (Brasil 2006), foram obtidos por meio da Guia de Trânsito Animal (GTA) do lote de animais. Por fim, os resultados dos exames realizados (macroscópico, histopatológico, bacteriológico e molecular) foram comparados a fim identificar as limitações e benefícios de cada metodologia.

As amostras foram clivadas de forma que cada fragmento da lesão abrangesse todas as camadas do granuloma, ou seja, o material necrótico, a cápsula e a área de transição entre a lesão e o tecido aparentemente normal. A seguir, foram submetidas às técnicas rotineiras de desidratação, diafanização e clarificação, inclusão em parafina e por fim, os blocos foram microtomizados a $4 \mu \mathrm{m}$, sendo obtidas duas lâminas histológicas de cada amostra. Uma lâmina foi corada pela HE com o propósito de observar alterações histopatológicas, enquanto a outra foi submetida à coloração de Ziehl-Neelsen para que fosse investigada a presença de bacilos álcool-ácido resistentes (BAAR) (Prophet et al. 1992).

As amostras mantidas a $-20^{\circ} \mathrm{C}$ foram organizadas em agregados, representando cada animal, processadas em até três meses e descontaminadas pelo método de cloreto de hexadecilpiridínio (HPC) a $0,75 \%$ e Petroff ( $\mathrm{NaOH}$ a $4 \%$ ) adaptado. 
Aproximadamente três gramas de cada amostra foram maceradas com vidro moído, por pistão de vidro, em tubos cônicos de $50 \mathrm{~mL}$ e então, submetidos aos métodos de descontaminação. A descontaminação por HPC $0,75 \%$ seguiu conforme descrito por Ambrosio e colaboradores (2008). 0 método de Petroff foi adaptado para que houvesse o tratamento simultâneo de até cinco amostras, respeitando-se a ordem de coleta e o abatedouro de origem (Ambrosio et al. 2008). Resumidamente, foi adicionado o mesmo volume de $\mathrm{NaOH}$ a $4 \%$ na suspensão das amostras maceradas. Quando houve isolamento, as amostras foram reprocessadas individualmente para a identificação das estirpes.

Após descontaminadas, amostras das culturas isoladas foram semeadas, em duplicata, em tubos contendo meio de Stonebrink e Löwenstein-Jensen e incubadas em estufa a $37^{\circ} \mathrm{C}$, sendo observadas semanalmente no primeiro mês e posteriormente, a cada duas semanas, até os 90 dias de cultivo. As colônias isoladas foram fotografadas e coradas para evidenciar a presença de BAAR, de acordo com as recomendações do manual nacional de vigilância laboratorial da tuberculose e outras micobactérias, do Ministério da Saúde do Brasil (2008).

Os BAAR isolados foram testados por meio da PCR múltipla (m-PCR), usando oligonucleotídeos iniciadores para amplificação das sequências genômicas RvD1Rv2031c e IS6110, específicas para M. bovis e para o complexo Mycobacterium tuberculosis, respectivamente. O DNA das colônias isoladas foi extraído por meio de lise térmica ( $100^{\circ} \mathrm{C}$ por $\left.10 \mathrm{~min}\right)$ e amplificado por $\mathrm{m}-\mathrm{PCR}$ conforme condições previamente estabelecidas (Figueiredo et al. 2009).

Fragmentos de tecido das lesões foram utilizados diretamente nas reações pela m-PCR, usando oligonucleotídeos para amplificação das sequências genômicas descritas anteriormente. A extração do DNA foi feita conforme descrito por Figueiredo e colaboradores (2010). Sessenta nanogramas de DNA total $(15 \mu \mathrm{L})$ foram utilizados como molde para amplificação das sequências alvo (RvD1Rv2031c e IS6110), baseado no método descrito por Figueiredo et al. (2009), modificado como se segue. Foram adicionados a mistura de reação $5 \mu \mathrm{l}$ de tampão (Invitrogen $囚$ ), $0,2 \mathrm{mM}$ dNTP (Fermentas $囚$ ), 1,5 U de Taq polimerase recombinante (Platinum ${ }^{\circledR}$ Taq - Invitrogen $\AA$ ), 20 pMol de cada primer (Invitrogen $\AA$ ) JB21 (5'-TCGTCCGCTGATGCAAGTGC-3') e JB22 (5'-CGTCCGCTGACCTC AAGAAAG-3') (Rodríguez et al. 1999) e INS1 (5'-CGTGAGGGCATCGAGGTGGC-3 ') e INS2 (5'-GCGTAGGCGTCGGTGACAAA- 3') (Hermans 1990) e 1,5mM $\mathrm{MgCl}_{2}$ (Invitrogen $囚$ ), em um volume final de $50 \mu \mathrm{L}$. A amplificação foi feita em um termociclador, modelo GeneAmp PCR System 9700 (Applied Biosystems () ) seguindo os seguintes parâmetros: $94^{\circ} \mathrm{C}$ por $5 \mathrm{~min}$, seguido por 37 ciclos de $1 \mathrm{~min}$ a $94^{\circ} \mathrm{C}$, 1 min a $68^{\circ} \mathrm{C}$ e $1 \mathrm{~min}$ a $72^{\circ} \mathrm{C}$, com uma extensão final a $72^{\circ} \mathrm{C}$ por $7 \mathrm{~min}$. Os produtos resultantes da PCR foram analisados por eletroforese em gel de agarose (Invitrogen $\AA)$ ) $1,5 \%$ corado com brometo de etídio $(10 \mathrm{mg} / \mathrm{mL})$.

\section{RESULTADOS}

Dentre os 41.193 bovinos examinados, 198 carcaças $(0,48 \%)$ apresentaram no total, 218 lesões nos linfonodos. Pela avaliação do SIF nenhuma carcaça apresentou lesão sugestiva de tuberculose, sendo julgadas como linfadenites comuns ou inespecíficas.

Ao exame histopatológico (HE) das 198 carcaças foram constatadas lesões do tipo granulomatosa em $83,8 \%$ delas, piogranulomatosa em 8,1\%, supurativas em 6,1\% e nos 2,0\% restantes, foram observadas outras lesões (como pneumonia intersticial). Entretanto, não foi observada a presença de BAAR em nenhuma das amostras.
Das 198 amostras processadas por HPC e cultivadas em meio Stonebrink foi evidenciado o crescimento de colônias com características compatíveis às de Mycobacterium bovis em apenas duas delas (1,0\%). Quando foi utilizado o método de descontaminação Petroff, foi possível isolar colônias de três (1,5\%) amostras, sendo duas destas provenientes das mesmas amostras tratadas com HPC.

Além do cultivo em Stonebrink, amostras tratadas por HPC e Petroff foram semeadas em meio Löwenstein-Jensen, na tentativa de isolar outras espécies de micobactérias. Entretanto, não houve o crescimento de colônias em nenhuma das amostras cultivadas neste meio.

As colônias isoladas das três amostras revelaram-se como BAAR quando coradas pela técnica de $\mathrm{ZN}$, e foram identificadas como $M$. bovis pela m-PCR. As lesões em que se verificou a presença de $M$. bovis estavam localizadas em linfonodos retrofaringeanos de três diferentes carcaças e no exame histopatológico ( $\mathrm{HE}$ ), foram classificadas como granulomatosa ou piogranulomatosa.

Não houve isolamento de micobactérias do restante das amostras classificadas como granulomatosa ou piogranulomatosa, que somadas, corresponderam a 92,0\% (182/198) do total. Embora o granuloma seja uma lesão clássica de tuberculose, não é considerada uma alteração patognomônica (Corner 1994, Neill et al. 1994, Reis et al. 1995, Brasil 2006). Isso pôde ser confirmado no presente estudo, pois $98,3 \%$ (179/182) das lesões encontradas com estas características não foram ocasionadas por $M$. bovis. Portanto, a presença do granuloma, observado no exame histopatológico, não é conclusiva, como parâmetro de diagnóstico de suporte da TB.

Quando a m-PCR foi empregada diretamente nos fragmentos de tecido (Fig.2), foi possível detectar a presença

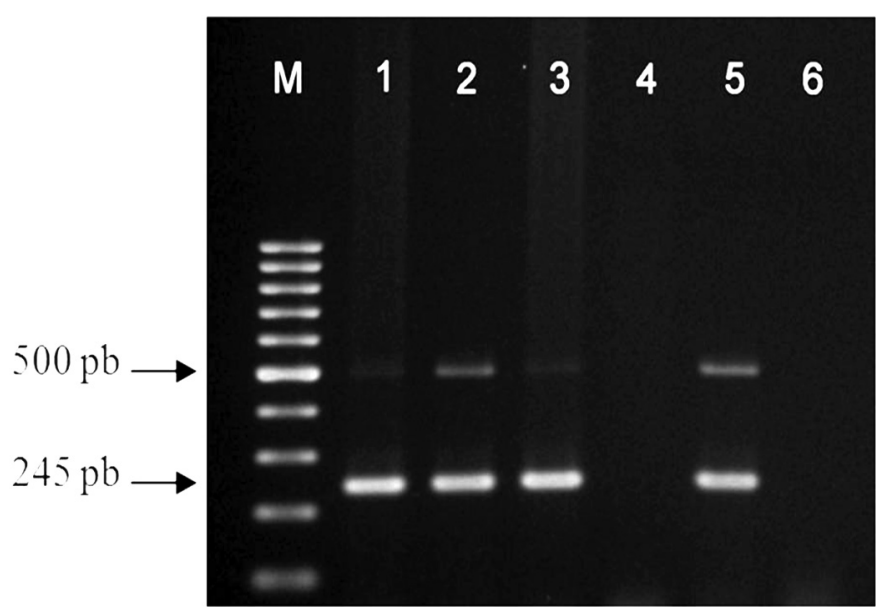

Fig.2. Detecção de DNA de Mycobacterium bovis por m-PCR direto de fragmentos de tecidos lesionados. DNA extraído de quatro lesões foram usados como molde para a amplificação por m-PCR das seqüências RvD1Rv2031c (500 pb) e IS6110 (245 pb). Linha M: marcador de tamanho de fragmento de DNA (100 pb); linhas 1, 2 e 3: produtos da m-PCR originada de lesões de tuberculose bovina encontradas em linfonodos retrofaringeanos de três carcaças inspecionadas em abatedouros no estado de Mato Grosso, Brasil; 4: reação representativa de uma lesão não ocasionada por M. bovis; 5: cepa de referência M. bovis (ATCC 19210), usada como controle positivo; 6: controle negativo. 
do DNA de $M$. bovis em 14 (7,0\%) amostras distintas, incluindo as mesmas três lesões a partir das quais foram isoladas cepas de $M$. bovis.

\section{DISCUSSÃO}

Sabendo que a classificação das lesões pode ser subjetiva e que existem fortes semelhanças entre as lesões provocadas em linfonodos pela tuberculose, linfossarcoma e linfadenites inespecíficas (Reis et al. 1995), foi adotado como critério, a coleta não apenas das lesões consideradas sugestivas de TB, mas de todas as linfadenites provenientes dos linfonodos da cabeça, cavidade torácica e região cervical da carcaça. A opção em estudar lesões localizadas nos linfonodos da porção dianteira da carcaça se deve a relatos de que até 86,0\% das lesões de TB ocorrem nos linfonodos da cabeça ou da cavidade torácica (Corner 1990, Whipple et al. 1996, Asseged et al. 2004).

No que se refere à distribuição das lesões na carcaça, foi constatada a ocorrência nos linfonodos pré-escapulares e pré-peitorais, em aproximadamente 73,2\% (145/198) do total (Quadro 1). Mesmo possuindo algum valor no diagnóstico da TB (Corner et al. 1990, Corner 1994), a maioria das lesões encontradas nesses linfonodos (Fig.1A) poderia ser atribuída à reação vacinal, pois, ao serem observadas pela coloração de HE, 84,5\% (126/145) apresentaram reação granulomatosa com vacúolos intralesionais (Fig.1B). Estes vacúolos são indicativos da presença de óleo mineral, possivelmente drenado do local da aplicação de vacinas, na musculatura da região cervical: "paleta" ou "pescoço", até ao linfonodo regional, onde se desencadeia a reação - ou seja, um efeito imunoestimulante esperado dos adjuvantes vacinais (Cox \& Coulter 1997). Esta hipótese se torna mais plausível, pois também não foram isoladas micobactérias a partir das lesões encontradas nos linfonodos pré-escapulares e pré-peitorais. Dessa maneira, acredita-se que os achados macroscópicos nestes linfonodos devam ser considerados apenas quando houver lesões sugestivas em outras regiões da carcaça e/ou histórico de tuberculose no rebanho.

Esperava-se que com o uso do método de descontaminação por HPC $(0,75 \%)$ houvesse isolamento de colônias em número superior ao obtido pelo método Petroff (Ambrosio et al. 2008, Medeiros 2009). Esta aparente discrepância poderia ser devido ao fato de cepas de $M$. bovis apresentarem sensibilidade diferente aos métodos de descontaminação empregados, considerando as especificidades bioquímicas dos agentes descontaminantes (Medeiros et al. 2009). Portanto, em análises deste tipo, ressalta-se a importância do uso de mais de um método de descontaminação.
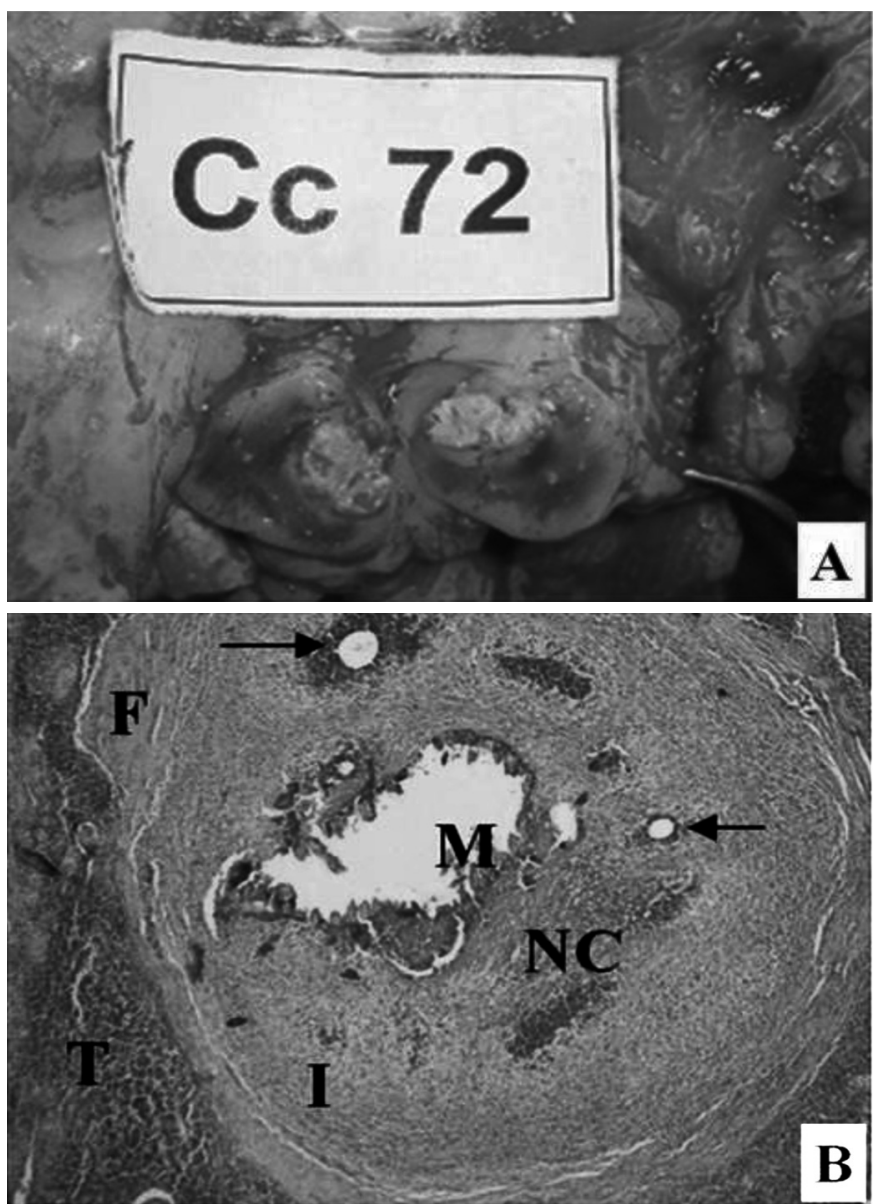

Fig.1. (A) Linfonodo pré-peitoral observado durante o exame post mortem em um abatedouro no estado de Mato Grosso, Brasil, com granuloma contendo massa caseosa de consistência pastosa, amarelada e calcificada, circundada por cápsula de tecido conjuntivo de aproximadamente $1 \mathrm{~cm}$. (B) reação granulomatosa caracterizada por necrose caseosa (NC) central com intensa mineralização (M) envolta por infiltrado predominantemente mononuclear (I), contendo vacúolos ocasionais intralesionais (seta). Lesão circundada por tecido conjuntivo fibroso (F) e bem delimitada em relação ao tecido íntegro (T). HE, obj. $5 x$.

Quadro 1. Lesões confirmadas e não confirmadas de tuberculose em carcaças bovinas abatidas entre maio a outubro de 2009 no estado de Mato Grosso, Brasil

\begin{tabular}{|c|c|c|c|c|c|}
\hline \multirow[t]{2}{*}{ Local da Lesão } & \multirow{2}{*}{$\begin{array}{l}\text { Numero de lesões } \\
\text { julgadas como linfa- } \\
\text { denites pelo S.I.F. }\end{array}$} & \multicolumn{2}{|c|}{$\begin{array}{c}\text { Identificação de } M \text {. bovis } \\
\text { por bacteriologia }\end{array}$} & \multicolumn{2}{|c|}{$\begin{array}{c}\text { Detecção de } M \text {. bovis } \\
\text { por m-PCR }\end{array}$} \\
\hline & & $\mathrm{N}^{\mathrm{o}}$ & $\%$ & $\mathrm{~N}^{\mathrm{o}}$ & $\%$ \\
\hline Pulmão & 5 & 0 & 0 & 1 & 0,5 \\
\hline Linfonodo apical & 4 & 0 & 0 & 1 & 0,5 \\
\hline Linfonodo mediastínico & 5 & 0 & 0 & 0 & 0 \\
\hline Linfonodo tráqueo-brônquico & 6 & 0 & 0 & 2 & 1,0 \\
\hline Linfonodo retrofaringeano & 22 & 3 & 1,5 & 5 & 2,5 \\
\hline Linfonodo pré-peitoral & 100 & 0 & 0 & 4 & 2,0 \\
\hline Linfonodo pré-escapular & 42 & 0 & 0 & 1 & 0,5 \\
\hline Linfonodo isquiático & 3 & 0 & 0 & 0 & 0 \\
\hline TOTAL & 198 & 3 & 1,5 & 14 & $7 \%$ \\
\hline
\end{tabular}


A ausência de BAAR nas lesões analisadas, situação idêntica à relatada por Salazar (2005), pode ser devido à baixa concentração de bacilos na lesão examinada, ou seja, lesões paucibacilares (Andrade et al. 1991). Essa constatação reforça a hipótese de que os três casos de tuberculose detectados por cultura, muito provavelmente foram isolados de animais com infecção recente, uma vez que os animais eram jovens (2-3 anos de idade) e provenientes de rebanhos de corte monitorados pelo PNCEBT.

Utilizando como molde fragmentos dos tecidos lesionados, a m-PCR detectou a presença de M. bovis em 14 (7,0\%) lesões, resultados condizentes com outros estudos similares Meikle et al. (2007); Cardoso et al. (2009) e Figueiredo et al. (2010). Adicionalmente, sugere-se que a maior sensibilidade da PCR poderia auxiliar a vigilância de TB em abatedouros. Com o uso da m-PCR foi possível diagnosticar a doença em dois dias de trabalho, tempo muito inferior ao necessário para a confirmação pelo método bacteriológico, que pode ser de até 90 dias.

De acordo com os resultados obtidos, aconselha-se o direcionamento da inspeção para os linfonodos da cavidade torácica e cabeça, em especial ao retrofaringeano, uma vez que, nessa região foram confirmadas a maioria das lesões de tuberculose (Quadro 1). Estudos anteriores também apontam para o grande envolvimento dos linfonodos retrofaringeanos $(22,9$ a $49,2 \%)$ nas lesões de tuberculose (Corner 1990, Milian-Suazo et al. 2000). Corner e colaboradores ainda relataram que, durante a inspeção sanitária em abatedouros, nos animais em que foi observada apenas uma lesão causada por $M$. bovis, o linfonodo retrofaringeano foi o local mais afetado, correspondendo a $43,9 \%$ de todos os casos avaliados.

Neste estudo, os linfonodos retrofaringeanos afetados apresentaram aumento de tamanho e as lesões foram verificadas por toda a sua intimidade (Fig.3 - A, B e C). Porém, as lesões eram de aspecto localizado, ou seja, restrito ao linfonodo, pois não foram constatadas outras alterações nas carcaças, que apresentaram escore corporal compatível para animais destinados ao abate. Em uma das lesões, o linfonodo lesionado estava preenchido por exsudato purulento (Fig.3A).

As lesões em que a presença de $M$. bovis foi confirmada foram julgadas pelo SIF como linfadenites comuns. Entretanto, o destino adotado (condenação parcial), foi condizente com as normas do artigo 196 do Regulamento de Inspeção Industrial e Sanitária de Produtos de Origem Animal - RIISPOA (Brasil 1952).

Usando a bacteriologia e a m-PCR como diagnóstico padrão, o exame macroscópico julgou as lesões encontradas de forma correta e precisa em 93,0\% (184/198) dos casos. No entanto, $M$. bovis foi identificado em 7,0\% (14/198) das amostras, não consideradas como tuberculosas.

Os resultados indicam que podem ocorrer equívocos durante o julgamento das lesões, principalmente entre as paucibacilares, como as encontradas no estudo, uma vez que estas não apresentam características clássicas de tuberculose, possivelmente devido ao fato dos animais doentes serem abatidos de forma precoce e com infecção recente. Isto poderia provocar uma distorção nas estimativas da
TB em abatedouros e traria consequências para o sucesso do PNCEBT, no que diz respeito à erradicação da tuberculose em regiões de baixa ocorrência. Nesses casos, o papel do serviço de inspeção, na vigilância da doença, seria fundamental para a detecção de focos remanescentes e no auxílio ao rastreamento de rebanhos infectados.

Os problemas encontrados, no entanto, não devem ser usados para julgar o desempenho do SIF, uma vez que absolutamente, apenas $14(0,03 \%)$ casos não foram identifi-
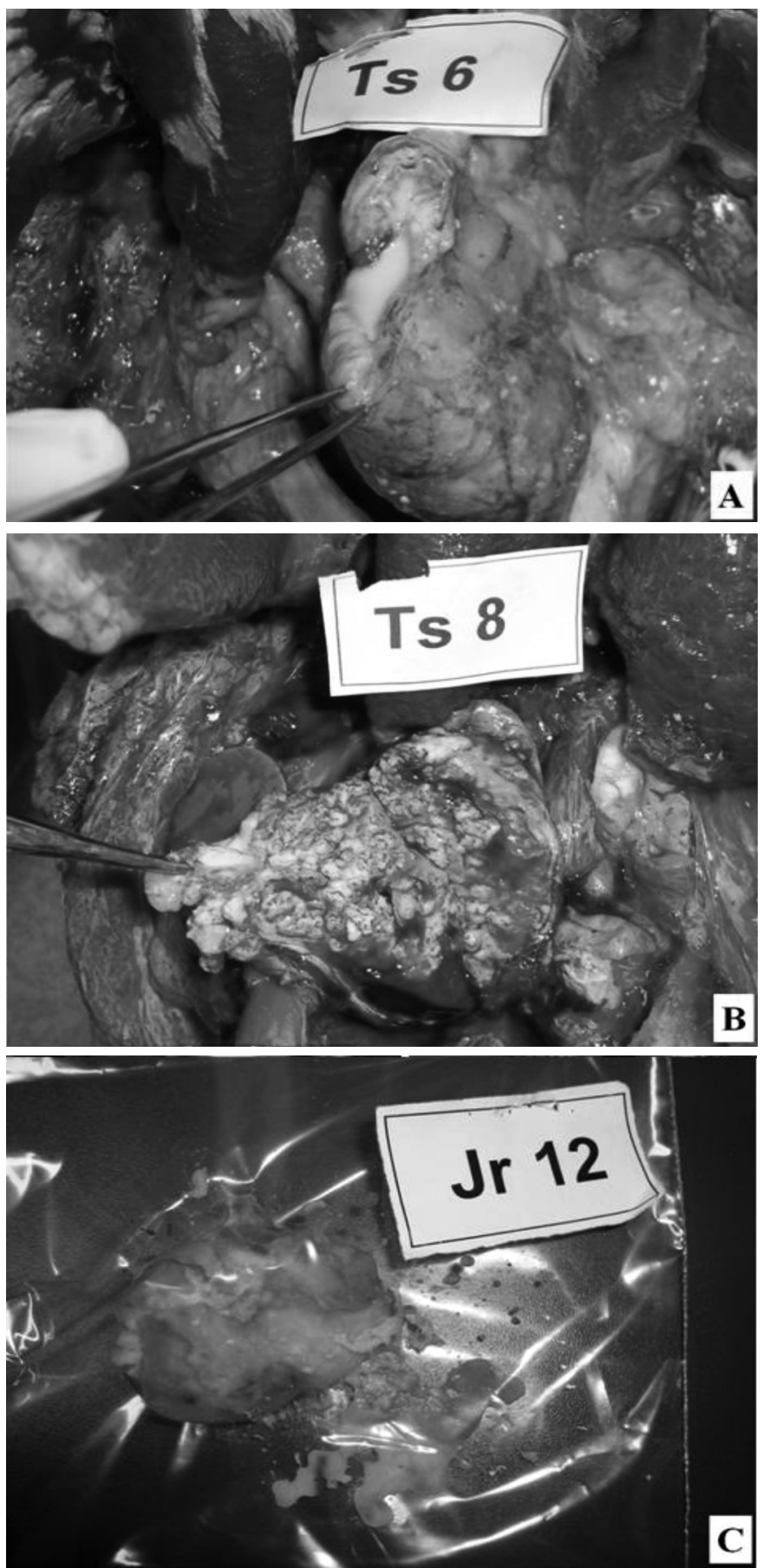

Fig.3. Lesões de tuberculose bovina coletadas durante o exame post mortem em sete abatedouros no estado de Mato Grosso, Brasil, entre maio e outubro de 2009. (A-C) Linfonodos retrofaringianos. 
cados corretamente, de um total de 41.193 animais inspecionados.

O exame macroscópico nos abatedouros é crucial para o diagnóstico de TB. Isto pode ser confirmado com base nos bons resultados alcançados pelos programas de controle, implementados em regiões com alta prevalência da doença (Corner 1994, Latini et al. 1997). Porém, à medida que a prevalência diminui, a identificação dos rebanhos remanescentes se torna progressivamente mais difícil. Embora atualmente não haja nenhum método de diagnóstico, ante ou post mortem, capaz de identificar todos os animais infectados com M. bovis, a detecção se torna mais sensível quando mais de um método de diagnóstico é usado (Whipple et al. 1996).

Assim, em regiões como o estado de Mato Grosso, onde a prevalência da doença é muito baixa (Furlanetto et al. 2012), deve-se alertar para as dificuldades encontradas pela inspeção post mortem no diagnóstico macroscópico de tuberculose e recomendar a adoção de testes complementares de diagnóstico rápido, como por exemplo, a aplicação da PCR diretamente em fragmentos de tecidos lesionados, proveniente de linfonodos frequentemente afetados, em especial do retrofaringeano. A implantação de eficientes sistemas de vigilância, adaptados à realidade local, podem contribuir para a detecção de focos remanescentes, acelerando o processo de erradicação de tuberculose no rebanho bovino dessas regiões.

\section{CONCLUSÕES}

Os resultados indicaram que equívocos ocorrem durante o julgamento das lesões suspeitas de tuberculose, principalmente entre as paucibacilares. Isto pode provocar uma distorção nas estimativas da TB em abatedouros e traria consequências para o sucesso do PNCEBT. Para minimizar equívocos no julgamento de tuberculose em abatedouros, recomenda-se a utilização de testes complementares de diagnóstico rápido nas lesões localizadas em regiões da carcaça frequentemente acometidas pela tuberculose, em especial do linfonodo retrofaringeano.

A m-PCR demonstrou ser uma técnica versátil, rápida e promissora na vigilância em abatedouros e poderia contribuir para o sucesso do PNCEBT no que tange ao rastreamento de focos remanescentes de TB.

Agradecimentos.- À FAPEMAT, FAPERJ, e CNPq pelo suporte financeiro, à Profa. Laura Peixoto da UNIC e ao Prof. Edson Moleta Colodel do Laboratório de Patologia Veterinária da Famev/UFMT pelo apoio nos exames histopatológicos, Prof. Rafael Duarte do Laboratório de Microbactérias do Instituto de Microbiologia da UFRJ pelo apoio nos exames bacteriológicos e a Superintendência Federal de Agricultura de Mato Grosso (SFA-MT/ MAPA) pela colaboração na obtenção de informações e amostras nos abatedouros.

\section{REFERENCIAS}

Abrahão R.M.C.M. 1999. Tuberculose humana causada pelo Mycobacterium bovis: considerações gerais e a importância dos reservatórios animais. Arch. Vet. Sci. 4:5-15.

Ambrosio S.R., Oliveira E.M.D., Rodriguez C.A.R., Ferreira Neto J.S. \& Amaku M. 2008. Comparison of three decontamination methods for Mycobacterium bovis isolation. Braz. J. Microbiol. 39:241-244.

Andrade G.B., Riet-Correa F., Mielke P.V., Méndez M.D.C. \& Schild A.L.
1991. Estudo histológico e isolamento de micobactérias de lesões similares à tuberculose em bovinos no Rio Grande do Sul. Pesq. Vet. Bras. 11:81-86.

Asseged B., Woldesenbet Z., Yimer E. \& Lemma E. 2004. Evaluation of abattoir inspection for the diagnosis of Mycobacterium bovis infection in cattle at Addis Adaba abattoir. Trop. Anim. Health Prod. 36:537-546.

Brasil 1952. Regulamento da Inspeção Industrial e Sanitária dos Produtos de Origem Animal. Decreto no 30691, de 29 de março de 1952, Ministério da Agricultura, Pecuária e Abastecimento, Brasília. 154p.

Brasil 2006. Programa Nacional de Controle e Erradicação da Brucelose e da Tuberculose Animal (PNCEBT): Manual técnico. Ministério da Agricultura, Pecuária e Abastecimento, Brasília. 184p.

Brasil 2008. Manual Nacional de Vigilância Laboratorial da Tuberculose e outras Micobactérias. Ministério da Saúde, Brasília. 436 p.

Cardoso M.A., Cardoso R.F., Hirata R.D.C., Hirata M.H., Leite C.Q.F., Santos A.C.B., Siqueira V.L.D., Okano W., Rocha N.S. \& Lonardoni M.V.C. 2009. Direct detection of Mycobacterium bovis in bovine lymph nodes by PCR. Zoonoses Publ. Health 56:465-470.

Corner L.A. 1994. Post mortem diagnosis of Mycobacterium bovis infection in cattle. Vet. Microbiol. 40:53-63.

Corner L.A., Melville L., McCubbin K., Small K.J., Mccormick B.S. \& Rothel J.S. 1990. Efficiency of inspection procedures for detection of tuberculous lesions in cattle. Aust. Vet. J. 67:389-392.

Cox J.C. \& Coulter A.R. 1997. Adjuvants: A classification and review of their modes of action. Vaccine 15:248-256.

Figueiredo E.E.S., Carvalho R.C.T., Silvestre F.G., Lilenbaum W., Fonseca L.S., Silva J.T. \& Paschoalin V.M.F. 2010. Detection of Mycobacterium bovis DNA in nasal swabs from tuberculous cattle by a multiplex PCR. Braz. J. Microbiol. 41:386-390.

Figueiredo E.E.S., Silvestre F.G., Campos W.N., Furlanetto L.V., Medeiros L., Lilenbaum W., Fonseca L.S., Silva J.T. \& Paschoalin V.M.F. 2009. Identification of Mycobacterium bovis Isolates by a multiplex PCR. Braz. J. Microbiol. 40:231-233.

Furlanetto L.V., Figueiredo E.E.S., Conte Júnior C.A., Silva F.G.S., Duarte R.S., Silva J.T., Lilenbaum W. \& Paschoalin V.M.F. 2012. Prevalência de tuberculose bovina em animais e rebanhos abatidos em 2009 no estado de Mato Grosso, Brasil. Arq. Bras. Med. Vet. Zootec. 64:274-280.

Hermans P.W., Van soolingen D., Dale J.W., Schuitema A.R., Mcadam R.A., Catty D. \& Van Embden J.D. 1990. Insertion element IS986 from Мусоbacterium tuberculosis: A useful tool for diagnosis and epidemiology of tuberculosis. J. Clin. Microbiol. 28:2051-2058.

Instituto Brasileiro de Geografia e Estatística (IBGE) 2007. Produção da Pecuária Municipal 2007: Bovinos - efetivo dos rebanhos. Disponível em <http://www.ibge.gov.br/cidadesat/topwindow.htm?1> Acesso em 31 jul. 2012.

Latini O., Canal A.M., Ferrara M.E., Sequeira M.D., Sequeira G., Bagnaroli R. \& Torres P. 1997. Confiabilidad en la determinación de prevalencia de infección por Mycobacterium bovis en ganado bovino por decomisos en frigoríficos. Arch. Med. Vet. 29:197-204.

Liebana E., Aranaz A., Mateos A., Vilafranca M., Gomez-Mampaso E., Tercero J.C., Alemany J., Suarez G. \& Domingo M. 1995. Simple and rapid detection of Mycobacterium tuberculosis complex organisms in bovine tissue samples by PCR. J. Clin. Microbiol. 33:33-36.

Medeiros L.S. 2009. Abordagem Multidisciplinar no Diagnóstico da Tuberculose Bovina. Universidade Federal Fluminense, Niterói. 75p.

Meikle V., Schneider M., Azenzo G., Zumarraga M., Magnano G. \& Cataldi A. 2007. Individual animals of a cattle herd infected with the same Mycobacterium bovis genotype shows important variations in bacteriological, histopathological and immune response parameters. Zoonoses Publ. Health. 54:86-93.

Milian-Suazo F., Salman M.D., Ramirez C., Payeur J.B., Rhyan J.C. \& Santillan M. 2000. Identification of tuberculosis in cattle slaughtered in Mexico. Am. J. Vet. Res. 61:86-89.

Neill S.D., Pollock J.M., Bryson D.G. \& Hanna J. 1994. Pathogenesis of Mycobacterium bovis infection in cattle. Vet. Microbiol. 40:41-51. 
Prophet E.B., Mills B., Arrington J.B. \& Sobin L.H. 1992. Laboratory Methods in Histotechnology. American Registry of Pathology, Washington. 279p.

Reis D.O., Almeida L. \& Faria A.R. 1995. Estudo comparativo entre linfossarcoma, tuberculose e linfadenites inespecíficas ocorridas em bovinos abatidos e a confirmação histológica. Hig. Alim. 35:28-30.

Rodríguez J.G., Fissanoti J.C., Del Portillo P., Patarroyo M.E., Romano M.I. \& Cataldi A. 1999. Amplification of a 500-basepair fragment from cultured isolates of Mycobacterium bovis. Eur. J. Clin. Microbiol. Infect. Dis. 37:2330-2332.

Salazar F.H.P. 2005. Ocorrência de tuberculose causada por Mycobacterium bovis em bovinos abatidos em frigoríficos no estado de Mato Gros- so, Brasil. Universidade Federal de Mato Grosso do Sul, Campo Grande. 73p.

Wards B.J., Collins D.M. \& Lisle G.W. 1995. Detection of Mycobacterium bovis in tissues by polymerase chain reaction. Vet. Microbiol. 43:227-240.

Whipple D.L., Bolin C.A. \& Miller J.M. 1996. Distribution of lesions in cattle infected with Mycobacterium bovis. J. Vet. Diagn. Invest. 8:351-354.

Zanini M.S., Moreira E.C., Lopes M.T.P., Oliveira R.S., Leão S.C., Fiovaranti R.L., Roxo E., Zumarraga M., Romano M.I., Cataldi A. \& Salas C.E. 2001. Mycobacterium bovis: polymerase chain reaction identification in bovine lymphonode biopses and genotyping in isolates from Southeast Brazil by spoligotyping and restriction fragment length polymorphism. Mem. Inst. Oswaldo Cruz 100:749-752. 